\title{
CONCEPTION AND DEVELOPMENT OF AN OPEN DATABASE SYSTEM ON HISTORICAL MULTILINGUALISM IN AUSTRIA
}

\author{
KATHARINA PROCHAZKA ${ }^{1}$ - LUDWIG MAXIMILIAN BREUER ${ }^{2,3,4}$ - AGNES KIM ${ }^{1}$ \\ ${ }^{1}$ Department of Slavonic Studies, University of Vienna, Austria \\ ${ }^{2}$ Austrian Centre for Digital Humanities, Austrian Academy of Sciences, Vienna, Austria \\ ${ }^{3}$ Department of German Studies, University of Vienna, Austria \\ ${ }^{4}$ Centre for Translation Studies, University of Vienna, Austria
}

PROCHAZKA, Katharina - BREUER, Ludwig Maximilian - KIM, Agnes: Conception and development of an open database system on historical multilingualism in Austria. Journal of Linguistics, 2019, Vol. 70, No 2, pp. 456 - 466.

\begin{abstract}
This paper discusses the development and structure of an online information system, which aims to gather and visualize data on historical multilingualism in Austria (German: historische Mehrsprachigkeit in Österreich, short: $\mathrm{MiÖ})$, with a particular focus on Slavic languages. The database tracks the development of multilingualism over time, its distribution in space and its representation in literature, therefore allowing to examine its dynamics and change. As an example, we investigate the area of the so-called Marchfeld ( $\check{c}$./sk. Moravské pole). The paper further discusses how the database is embedded into the collaborative research platform of the Special Research Program "German in Austria (DiÖ)" as well as its technical realization and the possibility to include data from other related research projects.
\end{abstract}

Keywords: online information system, historical multilingualism, language contact, Austria, Austria-Hungary

\section{INTRODUCTION: HISTORICAL MULTILINGUALISM IN AUSTRIA}

Present day Austria is generally perceived and constructed as a monolingual German-speaking country, with the exception of a few so-called autochthonous minorities (Slovenian in Carinthia and Styria, Burgenland Croatian, Hungarian and Romani in Burgenland and Vienna, Czech and Slovak in Vienna). This paper explores the alternative side of this assumption, focusing explicitly on (historical) multilingualism in Austria. Furthermore, the paper presents the development of a database, which allows to trace the dynamics and change of individual and societal multilingualism over time. The research is embedded within a larger project, the Special Research Program (SFB) "German in Austria (DiÖ). Variation - Contact Perception" (Austrian Science Fund/FWF F 60, [2]). The database presents the joint work of the project parts of Task Cluster C of the SFB (PP05 and PP06, both concerned with language contact of German with other languages, particularly with Slavic languages. The project is being developed with PP11, which realizes the 
collaborative online research platform "German in Austria" (for another relevant collaboration of these projects see [4]).

Historically, Austria was part of the Habsburg Empire, which was both multinational and multilingual. Following the Compromise of 1867, the Habsburg Empire was divided into two parts, the Austrian half and the Hungarian half. These were also known by their unofficial denotations: Cisleithania and Transleithania. Together, they were referred to as Austria-Hungary. The two parts were largely politically independent and pursued separate language policies. While Transleithania legally mandated Hungarian as the only official language, Cisleithania adopted a comparatively liberal acceptance of multilingualism. Multilingualism in Cisleithania encompassed individual and societal multilingualism, meaning that it can be classified as polycentric (see [9, p. 534]). Depending on the local hegemonic and linguistic constellations, it resulted in different forms of diglossia, specific to each crownland. German always played a role in the development of these diglossic situations, as a linguistic majority or minority in that area, or simply by virtue of being the lingua franca of Cisleithania (see [8, p. 314]). Other languages, however, also participated in various diglossic situations. Czech, for example, was not only spoken in Bohemia, Moravia and Austrian Silesia, but also in parts of Lower Austria. Within the latter, its status varied considerably between being the language of working migrants and the language of a village's majority (see [6]).

In this context, the projects of Task Cluster C study the contact of German in Austria mainly with Slavic languages, based on the core assumption that the complex historical multilingualism of Cisleithania played a significant role in shaping the current monolingual view of Austria and German in Austria. Because no typical scenario of multilingualism can be identified in Cisleithania, the two projects conduct case studies to gain a comprehensive perspective of the many facets of language use in Cisleithania. In order to achieve this, they work qualitatively as well as quantitatively. Multiple data sources are combined to overcome the so-called 'bad data problem' (inherent to historical sociolinguistics). ${ }^{1}$

In the following sections we will present the lexicographic database, representation of linguistic annotation.

\section{MIÖ: AN INFORMATION SYSTEM ON (HISTORICAL) MULTILIN- GUALISM IN AUSTRIA}

\subsection{Aims and goals}

A central aim of the SFB "German in Austria" is sustainability regarding data collection, processing, and provision for the scientific as well as the general public on a collaborative online research platform. Therefore, the data collected and processed in PP05 and PP06 are made accessible as a part of that platform. This part

\footnotetext{
${ }^{1}$ For further information on the methodology and sources of both projects, see [7].
} 
is concerned explicitly with multilingualism and is thus referred to as the Information system on (historical) multilingualism in Austria (German: Informationssystem zur [historischen] Mehrsprachigkeit in Österreich, short: MiÖ).

Currently, there is no comprehensive database encompassing data on (historical) multilingualism in Austria. MiÖ aims to close this gap by providing access to data related to historical multilingualism and its distribution. This includes information on the language skills of individuals and groups, as well as the sociolinguistic context (e.g. legal documents governing the teaching of languages in schools). MiÖ intends to facilitate further research by consolidating all the necessary information. Additionally, it equips its users with the ability to critically evaluate historical documents and sources of any kind by providing a comprehensive bibliography.

The aim of MiÖ is to present and visualize multilingualism in Austria along three axes that can be queried by the user. These constitute the common core of information for any data included (see Fig. 1):

1. its development over time: the dynamics and change of multilingualism can be viewed on a time axis, e.g. by searching for a year or a time span.

2. its distribution in space: data is geolocated to the respective places and/or regions to enable the visualization of linguistic data associated with a place (e.g. census data, data from linguistic questionnaires).

3. its representation in literature: a commented and indexed bibliography is available for any kind of data incorporated into MiÖ.

MiÖ is designed to be an open system that allows the integration of data on (historical) multilingualism from other research projects within separate modules and beyond the end of the SFB "German in Austria".

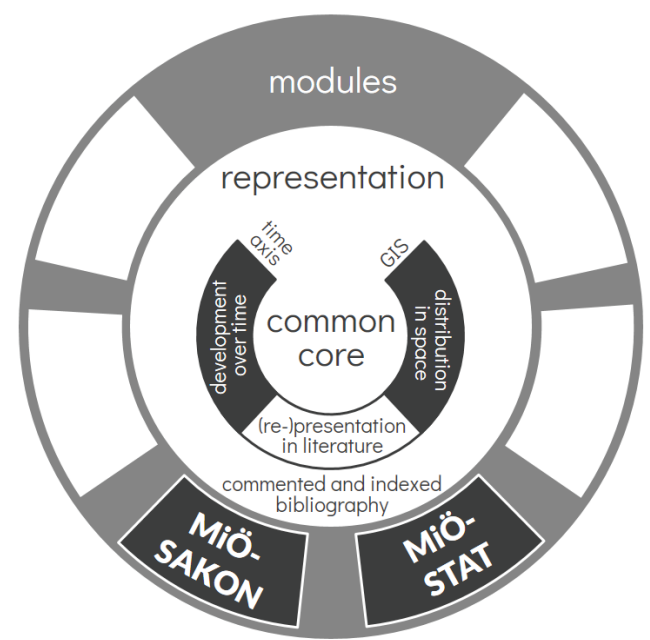

Fig. 1. Schematic overview of MiÖ; white spaces indicate the possibility to integrate further modules. 


\subsection{Modular structure}

In addition to the common core described above, MiÖ is organized in modules to retain maximal flexibility for expansion. In the first project phase of the SFB "German in Austria" (2016-2019), the realization of two modules is planned: MiÖSTAT (German: Statistische Informationen zur Mehrsprachigkeit in Österreich, 'Statistical Information on Multilingualism in Austria') and MiÖ-SAKON (German: Sprachliche Areal- und Kontaktphänomene im Deutschen in Österreich, 'Areal linguistic and contact phenomena in German in Austria'). These modules reflect the research foci of the two project parts involved, PP05 and PP06. The influence of contact with other languages on German in Austria is examined in terms of the linguistic layer (linguistic phenomena and variation, PP06) and from a sociolinguistic perspective (language contact scenarios, attitudes towards as well as perception and regulation of multilingualism, PP05). MiÖ-STAT is the first module to be realized within the MiÖ database. MiÖ-SAKON, the second module to be implemented, will provide a catalog of linguistic phenomena in varieties of German in Austria, which are typically ascribed to language contact (particularly with Slavic languages). It will allow users to check, whether a phenomenon can plausibly be explained by language contact or whether such a contact explanation is better described as a language myth. In the following sections, this paper will set aside MiÖ-SAKON and focus instead on the realization of MiÖ-STAT.

As its name suggests, MiÖ-STAT collects statistical information on language use in Austria(-Hungary) from a variety of sources. These data can be rather general (such as the census), or domain-specific (such as data on the linguistic background of students in elementary schools). The time axis of MiÖ-STAT commences in 1867, the year of the Austro-Hungarian Compromise. The covered area extends outside the borders of today's Austria, also encompassing parts of Cisleithania. MiÖ-STAT is aware of the bias which is inherent to language questions in statistical surveys. Both the phrasing of the question, as well as the political circumstances, considerably influence the self-reported behavior of the informants. Aside from this, surveys may be subject to irregularities, such as the forging of data (for the census in Cisleithania see [1]). MiÖ-STAT acknowledges these biases and consequently contextualizes the data sources with relevant literature.

Additionally, MiÖ-STAT collects and connects information from various sources, thus enabling users to compare them for individual places or entire regions. As shown in exemplary studies (see [5], [6]) such comparison allows for a transparent and more reliable reconstruction of the linguistic situation at a certain place at a specific time.

\subsection{Technical realization}

MiÖ is embedded within the larger collaborative online research platform of the SFB "German in Austria". While the other project parts provide recent selfcollected linguistic data (recordings of oral speech data and perception data from listener's judgment tests) for inclusion in the database, MiÖ is the only section 
working primarily with written historical documents at this stage. For this reason, the database structure has to be extended and adapted to manage the challenges of working with historical data. This mainly concerns the implementation of "time" in terms of an analyzable variable and an integrative component of the modeled information structure (e.g. change of names for places or regions, see below). Finally, all data generated or collected within the SFB "German in Austria" should be connected, to ensure that the data (historical and at some point also contemporary) on MiÖ can be analyzed in the context of the linguistic data on DiÖ and vice versa.

$\mathrm{MiÖ}$ integrates various types of data: (scientific) literature, statistical data (MiÖ-STAT, see above), information on linguistic phenomena (MiÖ-SAKON, see above) and their classification, among others. These can be described with regard to the information types reflected in the common core of MiÖ (see Fig. 1). As the data sources integrated into MiÖ are diverse, the database allows both the incorporation of the original documents (as scans or images where possible) and the machinereadable digitization of the information contained within.

The underlying database management system (DBMS) of the DiÖ online research platform is PostgreSQL ${ }^{2}$. This is implemented with the Django web framework ${ }^{3}$ that allows to model the data structure on a separate abstract layer, independent of the back-end. PostgreSQL is a widely used and well documented DBMS that provides many important functions (e.g. GIS extension, JSON integration). Its entire development is open source and published on GitHub ${ }^{4}$, which allows developers to share their tools directly with the community, simultaneously strengthening the sustainability of these tools, since it provides the possibility for maintaining and developing them even after the project is finished.

\subsection{Current status}

So far, the collaboration has focused primarily on the implementation of the back-end for the common core and the module MiÖ-STAT. MiÖ will be available via the browser interface of the DiÖ online research platform which is under development as of July 2019. In this section, we provide an example of how MiÖSTAT may support the research process concerning questions about sociolinguistic aspects of historical multilingualism in Austria.

As noted above, MiÖ-STAT includes statistical information that refers to certain places and stems from various sources. Fig. 2 shows a simplified data model of the underlying database. The core information, i.e., temporal, bibliographical and geographical information, is highlighted in grey. Additionally, Fig. 2 indicates that the module is embedded into MiÖ and the DiÖ research platform and how the information in MiÖ-STAT is linked to the DiÖ data.

\footnotetext{
${ }^{2}$ https://www.postgresql.org/

${ }^{3}$ https://www.djangoproject.com/

${ }^{4}$ https://github.com/german-in-austria/
} 


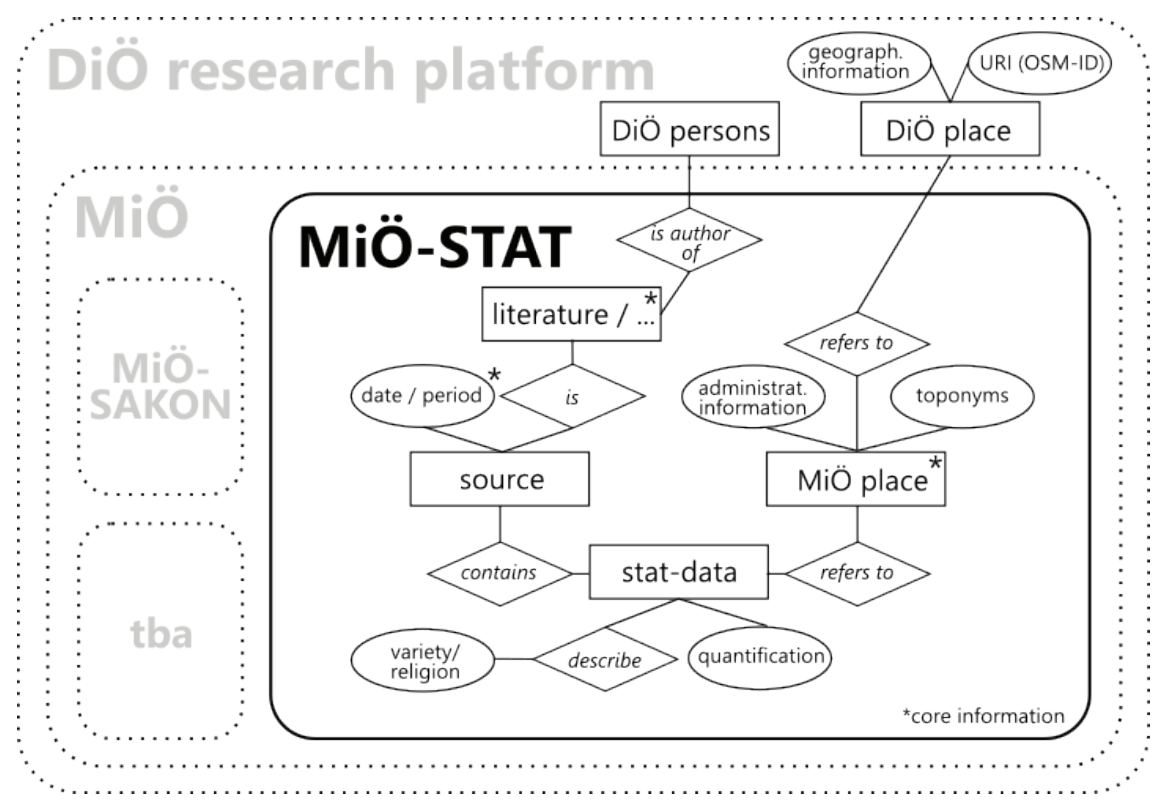

Fig. 2. Simplified entity-relationship model of MiÖ-STAT and its embedding into MiÖ and the DiÖ research platform

The model links contemporary places ${ }^{5}$ (in the DiÖ place-DB) to their historical equivalents (in the MiÖ place-DB) and allows to map their changing administrative affiliation and name changes. This is essential for the inclusion of data with varying resolution, as some sources do not provide information on single localities but only on the municipality or judicial district level. If possible, events (such as a change in administrative affiliation) are assigned exact dates (in the format DD.MM.YYYY) or time spans between two exact dates. Where exact temporal information is not available, as is usually the case with the publication date of books, the time span in which the event must have taken place is indicated.

Regarding the statistical information, MiÖ-STAT also strives to depict the original data source as accurately as possible. For example, the census for Cisleithania did generally not distinguish Czech from Slovak and referred to speakers of these languages as Čecho-Slaven 'Czecho-Slavs' in 1880. Therefore, the information is not directly linked to a language (variety, see [4]) or religion (denomination) but rather to the name for the respective language or religion used in the source (see [a] in Fig. 3).

${ }^{5}$ Regarding place terms, we distinguish several administrative levels (from the largest to the smallest, with Austrian terminology): country, crownland / state, political district, judicial district, municipality, locality. The smallest, i.e. the locality level, is our main point of reference. The larger entities are described as the sum of the smaller entities they comprise. Contemporary place terms are defined as such that officially existed on Jan. $1^{\text {st }}, 2018$. 
The input masks are optimized for easy entry of the statistical data and automatically sum up the entered numbers in order to enable immediate self-checks during the entry process (see [b] in Fig. 3).

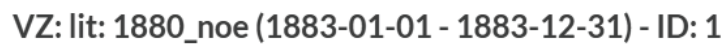

Ort: Loimersdorf, Bezirk Gänserndorf, Niederösterreich, 2292, Österreich - ID: 33

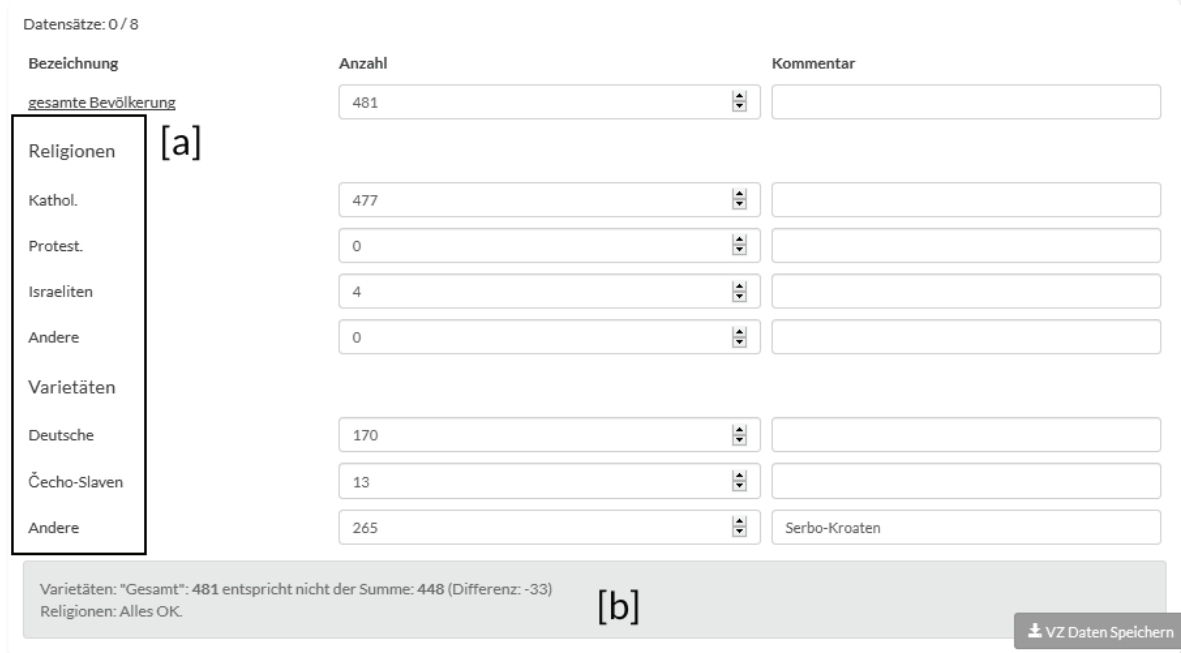

Fig. 3. Input mask for data from a specific census (1880) for a specific locality (Loimersdorf)

In the short run, MiÖ-STAT aims to achieve comprehensive high-resolution coverage of selected multilingual regions of the former Habsburg monarchy. In the long run, Austria within its current borders should, at least, be covered comprehensively. This goal is achieved by including census data per locality, which is subsequently enriched by other statistical data sources. In the area of the so-called Marchfeld (č./sk. Moravské pole) between Vienna and Bratislava, which has a size of approx. $900 \mathrm{~km}^{2}$, this yields 84 locations and hence 336 data points, if only the census data from 1880, 1890, 1900 and 1910 are included.

Queries made using the online accessible front-end will provide answers to questions such as: Where was Czech/Slovak ${ }^{6}$ spoken at a certain point in time? How did the percentage of Czech/Slovak speakers in certain places develop over a certain time period (see Fig. 4 for 1880 and 1910 for the Marchfeld)?

Maps, such as Fig. 4, help to visually identify places of interest at a certain point in time. Kim/Prochazka [7] have proposed a mathematical method to

${ }^{6}$ The Cisleithanian census did not differentiate between Czech and Slovak, but subsumed both languages under the glottonyms čechoslavisch 'czechoslavic' (1880) or böhmisch-mährisch-slovakisch 'Bohemian, Moravian, Slovak' (1890, 1900, 1910). 
formally determine places of interest across various points in time. It assumes that atypical changes in the percentage of speakers of other languages than German and foreigners ${ }^{7}$ shed light on the migration and assimilation history of a certain place. Moreover, locations with fluctuating patterns in the census results of the Habsburg monarchy may indicate a high degree of individual and societal bilingualism.

We have identified remarkable developments between $1880-1910$ by calculating the change of percentage of speakers using a language other than German and foreigners between two subsequent censuses. If the sum of the absolute values for all three time steps $(1880-1890,1890-1900,1900-1910)$ is larger than $20 \%$, we can assume that the development is remarkable. Regarding the Marchfeld, this procedure yields 26 places of special interest, i.e. $40 \%$ of the complete sample (see Fig. 5).

The inclusion of sources, other than the Cisleithanian census, such as earlier population counts (e.g. [3]), census data from the Inter-War period (1934) or linguistic questionnaires (e.g. Wenker's questionnaires, see [6]) provides new perspectives. The possibility to retrieve the data from the system will give the opportunity for further analyses. Thus, MiÖ-STAT will provide essential information to stimulate a closer and interdisciplinary scrutiny of historical multilingualism in Austria.

\subsection{Expandability and outlook}

An important goal is to design the DiÖ research platform and therefore MiÖ as an open system, which provides a link between the DiÖ/MiÖ data and alternative data and data types from other projects. Therefore, a standardized unique identifier (as object identifier) is essential to blend additional data with existing data and (geographical) entities. To this end, we employ longitude-/latitude-coordinates for identifying points or shapes in a geographical coordinate system (i.e., the World Geodetic System 1984, WGS84), as well as IDs provided by OpenStreetMap ${ }^{8}$ (as an open source tool with a transparent license) in combination with the object type (village, municipality, street etc.). This enables a convenient and globally unique identification of a geopolitical entity, not only in the position or shape of the entity but also regarding its (socio-)political information. ${ }^{9}$

${ }^{7}$ The Cisleithanian census only gave information on the so called Umgangssprache 'everyday language' of its citizens.

${ }^{8}$ https: / / www. openstreetmap.org/

${ }^{9}$ Another strategy to guarantee a high reusability and integration of the tools previously mentioned in section 2.3 is the implementation as a docker container (https://www.docker.com/), which can easily be integrated in various IT infrastructures without having to install all necessary dependencies. 


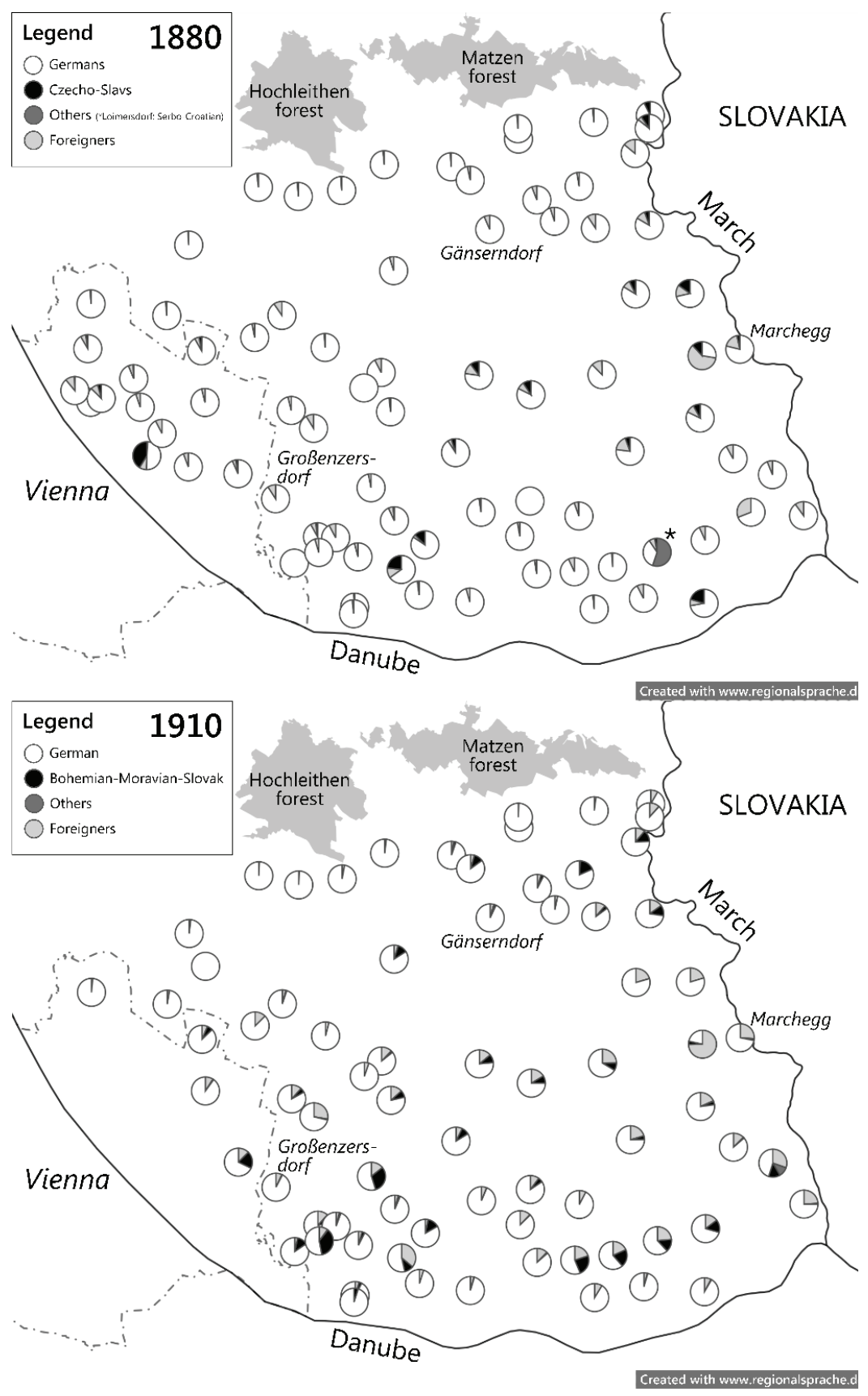

Fig. 4. Census results for all localities in the Marchfeld 1880 and 1910 (exemplary illustrations) 


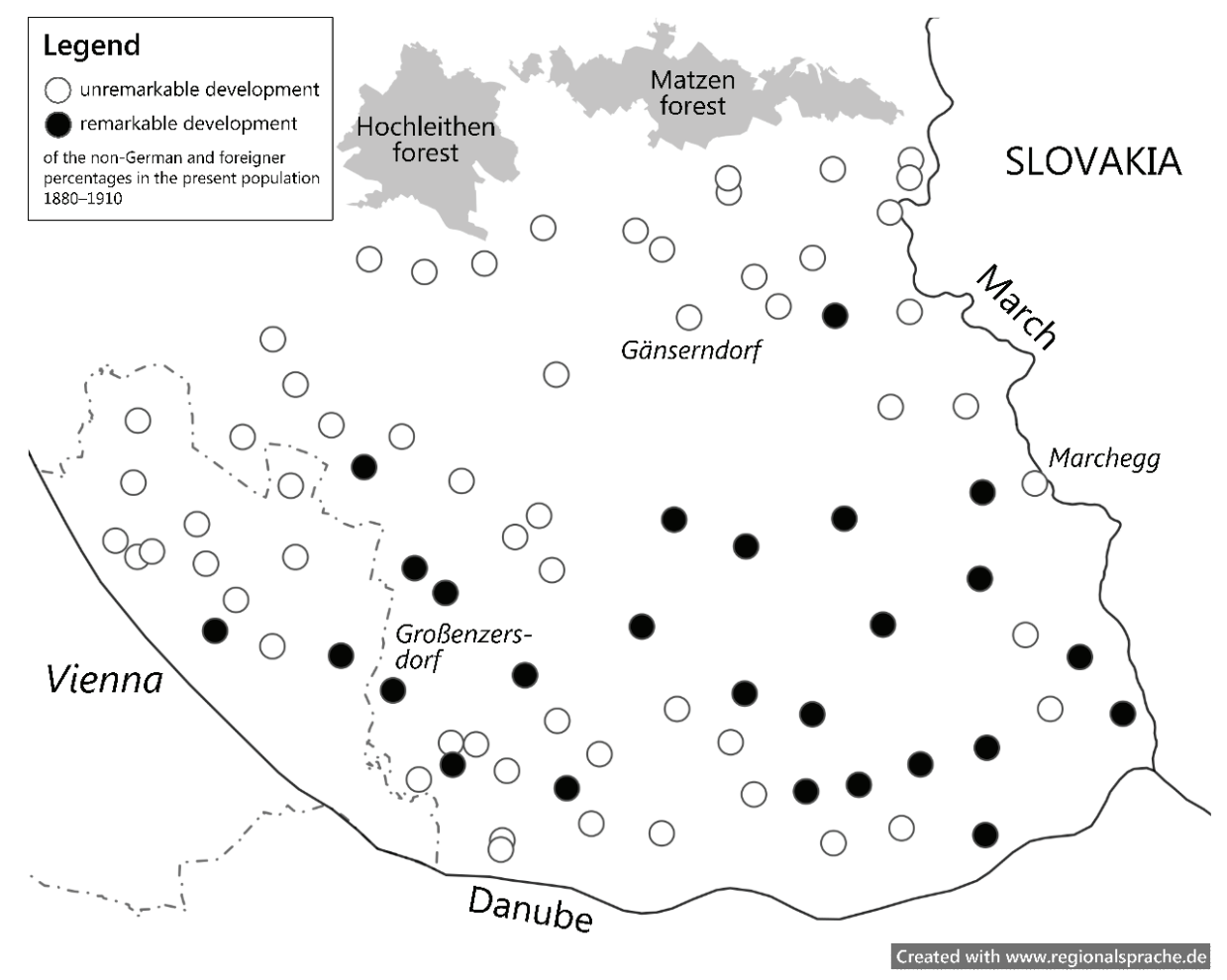

Fig. 5. Places of special interest in the Marchfeld (exemplary illustration)

Due to its open design, the database potentially allows for the direct input of data by other researchers (which can then be private or public and linked to the aforementioned unique identifiers). This is, however, a sensitive legal topic. Therefore, individual cases and the applicable licenses must be thoroughly explored before implementing this possibility.

As noted in section 2.1, the aim of the MiÖ (and DiÖ) database is to stimulate further research by using the data available in MiÖ (and the DiÖ research platform). To ensure flexibility and reuzability for the users, the database will include an export function in various formats (CSV, Excel, JSON) to ensure that the data can be easily analyzed and visualized in various contexts and research projects.

Ultimately, MiÖ strives to collect various types of data on (historical) multilingualism in Austria beyond its current borders. It aims to provide information for the reconstruction of historical, sociolinguistic contact scenarios and offer information regarding the seemingly factual knowledge concerning languages and multilingualism in Central Europe. 


\section{ACKNOWLEDGMENTS}

This work is supported financially by the Austrian Science Fund (FWF): F 60 "German in Austria (DiÖ). Variation - Contact - Perception". The MiÖ database is a collaboration between PP05 ("German in the context of the other languages in the Habsburg State [19 $9^{\text {th }}$ century] and $2^{\text {nd }}$ Austrian Republic", F 6005; PI: Stefan Michael Newerkla) and PP06 ("German and the Slavic languages in Austria: Aspects of language contact", F 6006, PI: Stefan Michael Newerkla). It is being developed collaboratively with PP11 ("Collaborative Online Research Platform”, F 6011; PI: Gerhard Budin).

The authors wish to thank Maria Schinko for help in digitizing and checking census data, Lena Katzinger and Katherine Jackson for proofreading and Stefan Michael Newerkla and Wolfgang Koppensteiner for comments on the manuscript.

References

[1] Brix, E. (1982). Die Umgangssprachen in Altösterreich zwischen Agitation und Assimilation. Die Sprachenstatistik in den zisleithanischen Volkszählungen 1880 bis 1910. Wien, Böhlau.

[2] Budin, G., Elspaß, S., Lenz, A. N., Newerkla, S. M., and Ziegler, A. (2018). Der Spezialforschungsbereich „Deutsch in Österreich (DiÖ). Variation - Kontakt - Perzeption“. Zeitschrift für Germanistische Linguistik 46(2), pages 300-308.

[3] Czoernig, K. (1857). Ethnographie der oesterreichischen Monarchie. Wien, Kaiserl. koenigl. Direction der administrativen Statistik.

[4] Kim, A., and Breuer L. M. (2017). On the development of an interdisciplinary annotation and classification system for language varieties. Challenges and solutions. Jazykovedný časopis 68(2), pages 191-207.

[5] Kim, A. (2018). Von „rein deutschen“ Orten und „tschechischen Minderheiten“. Spracheinstellungen und bevölkerungspolitisches Bewusstsein in den Wenkerbögen. In Philipp, H., Ströbl, A., Weber, B. and Wellner, J. (eds.). Deutsch in Mittel-, Ost- und Südosteuropa, pages 275-318, Regensburg, Universitätsbibliothek Regensburg.

[6] Kim, A. (2019). Multilingual Lower Austria. Historical sociolinguistic investigations on the Wenker questionnaires. In Bülow, L., Fischer, A.-K. and Herbert, K. (eds.). Dimensionen des sprachlichen Raumes. Variation - Mehrsprachigkeit - Konzeptualisierung, pages 187-211, Frankfurt am Main, Peter Lang Verlag.

[7] Kim, A., and Prochazka, K. (2019). Slawisch und Deutsch in Österreich. Methodische Ansätze zur Rekonstruktion historischen Sprachkontakts und seiner Einflüsse auf das Deutsch in Österreich. In Wiener Slavistisches Jahrbuch. N.F. 7, pages 1-27.

[8] Rindler Schjerve, R. (eds.) (2003). Diglossia and power. Language policies and practice in the $19^{\text {th }}$ century Habsburg Empire. Berlin/New York, Mouton de Gruyter.

[9] Stewart, W. A. (1968). A sociolinguistic typology for describing national multilingualism. In Fishman, J. A. (eds.): Readings in the Sociology of Language, pages 531-545, Berlin, de Gruyter. 